Dhaka Univ. J. Biol. Sci. 27(1): 57-68, 2018 (January)

\title{
MOLECULAR CHARACTERIZATION OF ACUTE HEPATOPANCREATIC NECROSIS DISEASE CAUSING VIBRIO PARAHAEMOLYTICUS STRAINS IN CULTURED SHRIMP PENAEUS MONODON IN SOUTH-WEST FARMING REGION OF BANGLADESH
}

\author{
Md Mostavi Enan Eshik, Nusrat Jahan Punom, Mst Khadiza Begum, Tahsin \\ $\mathrm{KHAN}^{1}$, MiHIR Lal SAHA ${ }^{1}$ AND Mohammad SHAMSUR RAHMAN* \\ Department of Fisheries, Faculty of Biological Sciences, \\ University of Dhaka, Dhaka-1000, Bangladesh
}

Key words: Vibrio parahaemolyticus, Penaeus monodon, AHPND, Shrimp disease

\begin{abstract}
Acute hepatopancreatic necrosis disease (AHPND) is an emerging shrimp disease caused by strains of Vibrio parahaemolyticus containing a unique virulent plasmid, responsible for substantial economic losses since 2009; caused up to $100 \%$ mortality in farmed shrimp Penaeus monodon. The purpose of this study was to isolate and identify the pathogenic strain of $V$. parahaemolyticus causing AHPND in cultured shrimp (Penaeus monodon) using classical and molecular techniques. Samples were collected from three different locations of south-west shrimp farming regions of Bangladesh viz. Sadar Upazilla of Satkhira; Mongla and Morrelganj under Bagerhat district. In this study, three selective media were used for primary isolation of $V$. parahaemolyticus. Among 46 primary isolates, 18 representative isolates were checked for the species-specific detection of $V$. parahaemolyticus using $l d h$ primers and all of them were found to be positive. $16 S$ rRNA gene sequencing were used to further confirm the isolates as $V$. parahaemolyticus. $t$ dh primer was used to check human pathogenicity but all 18 isolates showed negative result. The isolates were further characterized to check their AHPND positivity using AP3 and AP4 primers. Ten isolates showed positive results for AP3 (55.56\%) and 9 showed positive results for AP4 (50\%) which indicated that the isolates were AHPND positive. This study also reported that all AHPND positive strains were resistant to the antibiotic gentamycin but sensitive to chloramphenicol, nalidixic acid, nitrofurantoin and tetracycline. The findings of this study will help the shrimp farmers and policy makers to take proper biosecurity measures to protect shrimps from AHPND and thereby sustain the shrimp production in Bangladesh.
\end{abstract}

\section{Introduction}

The shrimp aquaculture industry is continuously growing and accounts for $15 \%$ of the internationally traded seafood products ${ }^{(1)}$. Farmed shrimp account for $57 \%$ of the total shrimp consumed globally (7.9 million tons) $)^{(1)}$. China, Vietnam, Thailand and Bangladesh

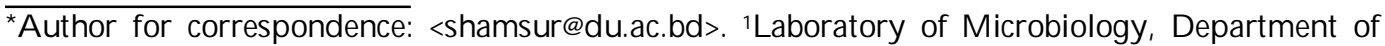
Botany, Faculty of Biological Sciences, University of Dhaka, Dhaka-1000, Bangladesh. 
are the major shrimp producing countries ${ }^{(1)}$. Although global shrimp production has increased from approximately one million tons in 2000 to four million tons in 2011, the production level of 2015 was expected to be 15\% below that of 2011 due to disease outbreaks causing significant production losses ${ }^{(1)}$. Asian shrimp farming industry has experienced massive production losses due to a disease caused by toxins of Vibrio bacteria, known as early mortality syndrome/acute hepatopancreatic necrosis disease (EMS/AHPND) for the last 5 years $^{(2)}$. It is estimated that about $60 \%$ of disease losses in shrimp aquaculture have been caused by viral pathogens and only $20 \%$ by bacterial pathogens ${ }^{(3)}$; but this emerging disease AHPND may shift this scenario in favor of bacteria. This disease has recently caused serious production loss in the shrimp culture industry. It most frequently occurs within the first 30 days after stocking a newly prepared shrimp pond. It was first reported in China in 2009 and then spread to Vietnam, Malaysia and Thailand(4). AHPND affects both Penaeus monodon (Fabricius) and Litopenaeus vannamei (Boone). Certain strains of $V$. parahaemolyticus belonging to the Harveyi clade are responsible for pathological changes in the hepatopancreas (HP) of AHPND affected animals(5). Vibrio parahaemolyticus is a halophilic Gram-negative bacterium that is a normal inhabitant of marine environment. Most of the $V$. parahaemolyticus isolated from the marine environments are non-pathogenic strains. AHPND suspected shrimps show gross signs of abnormal HP with significant atrophy and discoloration when compared with the normal shrimps(4). The histopathology of AHPND is characterized by massive cell sloughing of HP tubule epithelial cells together with the dysfunction of B, F, R and E cells of HP of affected shrimps( ${ }^{(6)}$. Detection of $V$. parahaemolyticus isolates is typically based on molecular biological analysis that amplify species-specific gene $l d h$ (lecithin dependent hemolysin)(7) and $t d h$ (thermostable direct hemolysin) ${ }^{(8)}$ gene is amplify to detect human pathogenicity. Among all sequencing platforms, 16S rRNA sequencing technology provides large enough length (1500 bp) for informatics purposes and has been used to investigate bacterial phylogeny and taxonomy ${ }^{(9,10)} \cdot \mathrm{AP}^{(11)}$ and $\mathrm{AP} 4^{(12)}$ primers are usually used to characterize AHPND positive strains of $V$. parahaemolyticus.

The aim of the study was to isolate and characterize AHPND positive $V$. parahaemolyticus from shrimp farms of Bangladesh using molecular techniques. Moreover, construction of phylogenetic tree using 16S rRNA gene sequencing, human pathogenicity and antibiotic susceptibility of the isolated bacteria were also performed.

\section{Materials and Methods}

Twenty seven shrimp samples from 20 shrimp farms (locally known as Ghers) were collected from Sadar Upazilla of Satkhira district and two Upazilla (Morrelganj and Mongla) of Bagerhat district and immediately transported to the laboratory. To lower the temperature $\left(4^{\circ} \mathrm{C}\right)$ during transportation, ice was placed around the bags. The shrimp 
samples were processed and hepatopancreas were collected within 12 hours of collection following aseptic techniques ${ }^{(13)}$.

Sampling of hepatopancreas was done carefully to avoid contamination with intestinal bacteria and serial dilutions was done in sterile saline solution. Three selective agar media viz., TCBS (Thiosulphate Citrate Bile Salt Sucrose Agar), Hi Chrome Vibrio agar and Chrom Agar Vibrio were used for culturing bacteria after enrichment in alkaline peptone water (APW). After incubation at $37^{\circ} \mathrm{C}$, characteristic single colonies were picked up and streaked on TCBS agar and Chrom Agar Vibrio plates and incubated at $37^{\circ} \mathrm{C}$ overnight. Green and pure purple colored colonies were selected and were streaked onto Tryptic Soya Agar (TSA) with $2 \%$ salt for purity assurance. Pure isolates were preserved in LB media with $30 \%$ glycerol and frozen at $-80^{\circ} \mathrm{C}$ for further studies.

After DNA extraction following Rahman et al.(14) suspected colonies were analyzed for the presence of the species-specific molecular markers of $V$. parahaemolyticus, i.e. $l d h$ as described by Taniguchi et al.(7). 16S rRNA gene sequencing of about $1500 \mathrm{bp}$ was used for further confirmation of the isolates as V. parahaemolyticus. Universal primers for $16 \mathrm{~S}$ rRNA amplification are listed in Table 1. PCR reaction mixture and thermal cycling condition were done following Punom et al. (15).

Amplified DNA was further purified with the Wizard PCR SV Gel and PCR CleanUp System (Promega, USA) according to the manufacturer instruction prior to sequencing. Sequencing of PCR product was performed using Big Dye Terminator v 3.1 Cycle sequencing Kit (Applied Biosystems, USA) according to manufacturer instruction and capillary electrophoresis was done using ABI Genetic Analyzer (Applied Biosystems, USA). To view DNA sequence, Geospizas Finch TV version 1.4 was used. BLAST (Basic Local Alignment Search Tool) was used for comparing primary sequence information. MEGA v 6.0(16) was used for the comparative analysis of molecular sequence data for reconstructing the evolutionary histories of species and inferring the phylogeny by using the Maximum Likelihood method based on the Tamura-Nei model(17).

Only isolates positive for $l d h$ and confirmed by $16 \mathrm{~S}$ rRNA sequencing were further analyzed by PCR with $t d h^{(8)}$ to check the human pathogenicity. AP3 and AP4 (nested) primers were used to check the AHPND positivity as described by Sirikharin et al.(11) and Dangtip et al.(12), respectively. These primers target contigs that belong to a plasmid in AHPND positive pathogenic strains of $V$. parahaemolyticus. A list of primers to identify and characterize AHPND positive $V$. parahaemolyticus is given in Table 1.

The Kirby-Bauer disc diffusion technique ${ }^{(18)}$ was performed to determine the sensitivity or resistance of pathogenic bacteria to 14 antibacterial compounds (list of 14 antibiotic discs is given in Table 4). Eighteen representative isolates were inoculated on Muller-Hinton Broth (MHB) (Oxoid, USA) and incubated for $24 \mathrm{hrs}$ and then the bacterial suspension was spreaded onto the surface of the Muller-Hinton Agar (MHA) using sterile cotton swabs, which were then left to dry for several minutes. The antibiotic discs 
(Oxoid, USA) were applied on the surface of the agar plate and incubated for $24 \mathrm{hrs}$ at $37^{\circ} \mathrm{C}$. Finally, the zone of inhibition was measured to detect susceptibility of the bacteria.

Table 1. List of primers to identify and characterize AHPND positive V. parahaemolyticus.

\begin{tabular}{|c|c|c|c|c|}
\hline Sl. & Primers & Sequence & Purpose & References \\
\hline 1 & $l d h$ & $\begin{array}{l}\text { 5`-AAAGCGGATTATGCAGAAGCACTG-3` } \\
\text { 3`-GCTACTTTCTAGCATTTTCTCTGC-5` }\end{array}$ & $\begin{array}{l}\text { To detect } V \text {. } \\
\text { parahaemolyticus } \\
\text { haemolysin gene }\end{array}$ & Taniguchi et al.(7) \\
\hline 2 & $16 \mathrm{~S}$ rRNA & $\begin{array}{l}\text { 5'-GCCTAACACATGCAAGTCGA-3' } \\
\text { 5'-GACTACCAGGGTATCTAATCC-3' }\end{array}$ & $\begin{array}{l}\text { To further } \\
\text { confirm } V \text {. } \\
\text { parahaemolyticus } \\
\text { isolates }\end{array}$ & $\begin{array}{l}\text { Lane }^{(9)} \\
\text { Frank et al. } .^{(10)}\end{array}$ \\
\hline 3 & $t d h$ & $\begin{array}{l}\text { 5`-GTACCGATATTTTGCAAA-3` } \\
\text { 3`-ATGTTGAAGCTGTACTTGA-5` }\end{array}$ & $\begin{array}{l}\text { To detect the } \\
\text { human } \\
\text { pathogenicity }\end{array}$ & Bej et al. ${ }^{(8)}$ \\
\hline 4 & AP3 & $\begin{array}{l}\text { 5'-ATGAGTAACAATATAAAACATGAAAC-3' } \\
5^{\prime} \text {-GTGGTAATAGATTGTACAGAA-3' }\end{array}$ & $\begin{array}{l}\text { To detect ToxA } \\
\text { and Tox } \mathrm{B} \text { gene }\end{array}$ & Sirikharin et al..$^{(11)}$ \\
\hline 5 & $\begin{array}{l}\text { AP4-F1* } \\
\text { AP4-R1 }\end{array}$ & $\begin{array}{l}\text { 5'-ATGAGTAACAATATAAAACATGAAAC-3` } \\
\text { 3`-ACGATTTCGACGTTCCCCAA-5` }\end{array}$ & $\begin{array}{l}\text { To detect ToxA } \\
\text { and Tox } \mathrm{B} \text { gene }\end{array}$ & Dangtip et al..$^{(12)}$ \\
\hline & $\begin{array}{l}\text { AP4-F2 } \\
\text { AP4-R2 }\end{array}$ & $\begin{array}{l}\text { 5'-TTGAGAATACGGGACGTGGG-3` } \\
\text { 3`-GTTAGTCATGTGAGCACCTTC-5` }\end{array}$ & $\begin{array}{l}\text { To detect } \\
\text { ToxA gene plus } \\
12 \text { bp spacer } \\
\text { sequence plus } 9 \\
\text { bpToxB gene }\end{array}$ & Dangtip et al..$^{(12)}$ \\
\hline
\end{tabular}

*Primer AP4-F1 is identical to primer AP3-F from the AP3 method.

Nucleotide sequence accession numbers: The reported sequences in this study have been submitted to NCBI GenBank database under accession numbers KY565404-KY565421.

\section{Results and Discussion}

Three types of selective culture media were used for primary isolation of $V$. parahaemolyticus. Forty six V. parahaemolyticus strains were isolated from 27 shrimp samples based on colony morphology (Green Colonies on TCBS plate, Violet Colonies on Chrom Agar Vibrio and Bluish green Colonies on HiChrome Vibrio Agar).

Eighteen representative isolates (Vp2, Vp4, Vp6, Vp7, Vp9, Vp11, Vp21, Vp23, Vp24, Vp25, Vp26, Vp27, Vp30, Vp35, Vp38, Vp39, Vp42 and Vp43) were used for the detection of $V$. parahaemolyticus by using species specific $l d h$ primer. Detection for $l d h$ gene fragment showed positive result for all 18 representative isolates.. In a study on AHPND of shrimp, Joshi et al.(7) identified six bacterial isolates as $V$. parahaemolyticus by lecithin dependent hemolysin $(l d h)$ gene primer. 
The amplified PCR products (Fig. 1) were sequenced and aligned with the 16S rRNA gene sequences in GenBank and the sequences showed (>99\%) homology with the 16S rRNA gene of $V$. parahaemolyticus strains. The identification of the 16S rRNA gene sequences of 18 representative isolates through nucleotide BLAST of NCBI is summarized on Table 2.
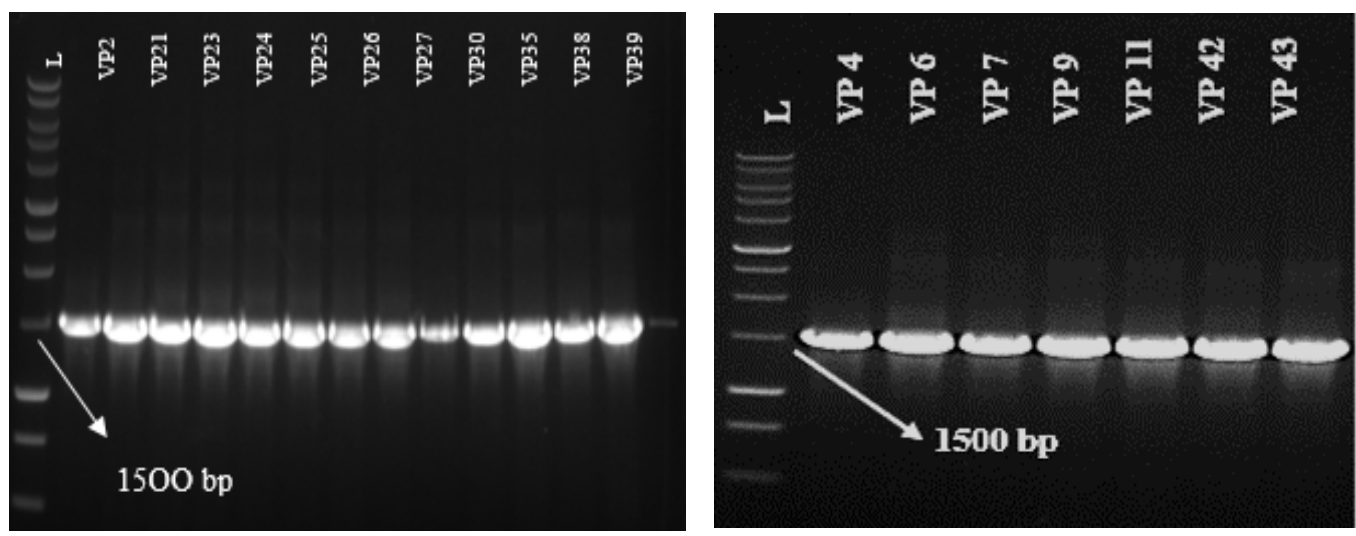

Fig. 1. PCR amplification of $16 \mathrm{~S}$ rRNA gene of 18 representative isolates of $V$. parahaemolyticus and

$\mathrm{L}$ denotes DNA ladder of $1 \mathrm{~kb}$ marker.

Phylogenetic tree was constructed using 16S rRNA gene sequences of 18 representative isolates of this study and 9 sequences were downloaded from NCBI GenBank. The taxonomic position of all 18 representative isolates was confirmed as $V$. parahaemolyticus according to the phylogenetic tree (Fig. 2). The isolates clustered with various strains of $V$. parahaemolyticus rather other Vibrio strains. Aliivibriofischeri strain CZB-30 was used as an out group during phylogenetic reconstruction. In a study, Joshi et al.(6) also analyzed their isolates with 16S ssurRNA gene sequences and found their isolates gave $99 \%$ similarity with $V$. parahaemolyticus. Present investigation strongly suggests that the presumptive identification of the isolates through selective media was confirmed as the strains of $V$. parahaemolyticus.

Representative 18 confirmed $V$. parahaemolyticus isolates were then used for the detection of human pathogenicity by using $t d h$ primer. Detection for $t d h$ gene fragment showed negative results for all the isolates. Xu et al. ${ }^{(19)}$ worked on $145 \mathrm{~V}$. parahaemolyticus isolates to confirm and test for the presence of $t d h$. But they found that none of the isolates possessed the genes. Soto-Rodriguez et al.(20) confirmed 37 isolates as $V$. parahaemolyticus using th but those isolates were found negative for the human-toxigenic genes $t d h$ and $t r h$. 
Table 2. Similarity of sequences of $16 \mathrm{~S}$ rRA gene of representative isolates of this study with those obtained from BLAST search.

\begin{tabular}{|c|c|c|c|c|c|c|c|c|}
\hline $\begin{array}{l}\mathrm{Sl} \\
\text {.No } \\
.\end{array}$ & $\begin{array}{l}\text { Sample } \\
\text { ID }\end{array}$ & $\begin{array}{l}\text { Sampling } \\
\text { area }\end{array}$ & $\begin{array}{l}\text { Isolates } \\
\text { ID }\end{array}$ & Description & $\begin{array}{l}\text { BLAST } \\
\text { Score }\end{array}$ & $\begin{array}{l}\text { Identity } \\
(\%)\end{array}$ & $\begin{array}{l}\text { GenBank } \\
\text { accession no. }\end{array}$ & $\begin{array}{l}\text { Accession } \\
\text { no. of our } \\
\text { strains }\end{array}$ \\
\hline 1 & $\mathrm{SH} 1$ & Satkhira & $\mathrm{Vp} 2$ & Vibrio parahaemolyticus strain ECSMC9 & 2555 & 99 & KU845385.1 & KY565404 \\
\hline 2 & AH2 & Satkhira & Vp4 & Vibrio parahaemolyticus strain CHB-35 & 2560 & 99 & KR347292.1 & KY565405 \\
\hline 3 & MiH3 & Satkhira & Vp6 & Vibrio parahaemolyticus strain Xmb045 & 2549 & 99 & KT986171.1 & KY565406 \\
\hline 4 & $\mathrm{OH} 4$ & Satkhira & Vp7 & Vibrio parahaemolyticus strain NSP1 & 2555 & 99 & JN188415.1 & KY565407 \\
\hline 5 & BH5 & Satkhira & Vp9 & Vibrio parahaemolyticus strain XG409 & 2549 & 99 & JQ948037.1 & KY565408 \\
\hline 6 & M2H6 & Satkhira & Vp11 & Vibrio parahaemolyticus strain M2-31 & 2549 & 99 & KC210810.1 & KY565409 \\
\hline 7 & AnH1 & Satkhira & Vp21 & Vibrio parahaemolyticus strain M2-11 & 2560 & 99 & KC210810.1 & KY565410 \\
\hline 8 & $\mathrm{AbH} 2$ & Satkhira & Vp23 & Vibrio parahaemolyticus strain $\mathrm{CHB}-5$ & 2555 & 99 & KR347274.1 & KY565411 \\
\hline 9 & $\mathrm{AbH} 2$ & Satkhira & Vp24 & $\begin{array}{l}\text { Vibrio parahaemolyticus strain } \\
\text { Aj2010072802A90 }\end{array}$ & 2560 & 99 & JF432066.1 & KY565412 \\
\hline 10 & $\mathrm{AbH} 2$ & Satkhira & Vp25 & $\begin{array}{l}\text { Vibrio parahaemolyticus strain } \\
\text { FORC_018 }\end{array}$ & 2555 & 99 & СР013826.1 & KY565413 \\
\hline 11 & $\mathrm{BaH} 1$ & Satkhira & Vp26 & Vibrio parahaemolyticus strain LA1 & 2555 & 99 & KC884619.1 & KY565414 \\
\hline 12 & Shw1 & Satkhira & Vp27 & Vibrio parahaemolyticus strain $\mathrm{CZN}-9$ & 2560 & 100 & KR347248.1 & KY565415 \\
\hline 13 & $\mathrm{AbW} 1$ & Satkhira & Vp30 & Vibrio parahaemolyticus strain $\mathrm{CHB}-40$ & 2555 & 99 & KR347297.1 & KY565416 \\
\hline 14 & BaHM & Bagerhat & Vp35 & Vibrio parahaemolyticus strain CZN-34 & 2549 & 99 & KR347270.1 & KY565417 \\
\hline 15 & MiHB & Bagerhat & Vp38 & Vibrio parahaemolyticus strain CZN-9 & 2555 & 99 & KR347248.1 & KY565418 \\
\hline 16 & MeHB & Bagerhat & Vp39 & Vibrio parahaemolyticus strain CHB-33 & 2549 & 99 & KR347290.1 & KY565419 \\
\hline 17 & AfHB & Bagerhat & Vp42 & Vibrio parahaemolyticus strain NSTH2 1 & 2549 & 99 & KF886632.1 & KY565420 \\
\hline 18 & SeHB & Bagerhat & Vp43 & Vibrio parahaemolyticus strain $\mathrm{CZN}-7$ & 2555 & 99 & KR347246.1 & KY565421 \\
\hline
\end{tabular}




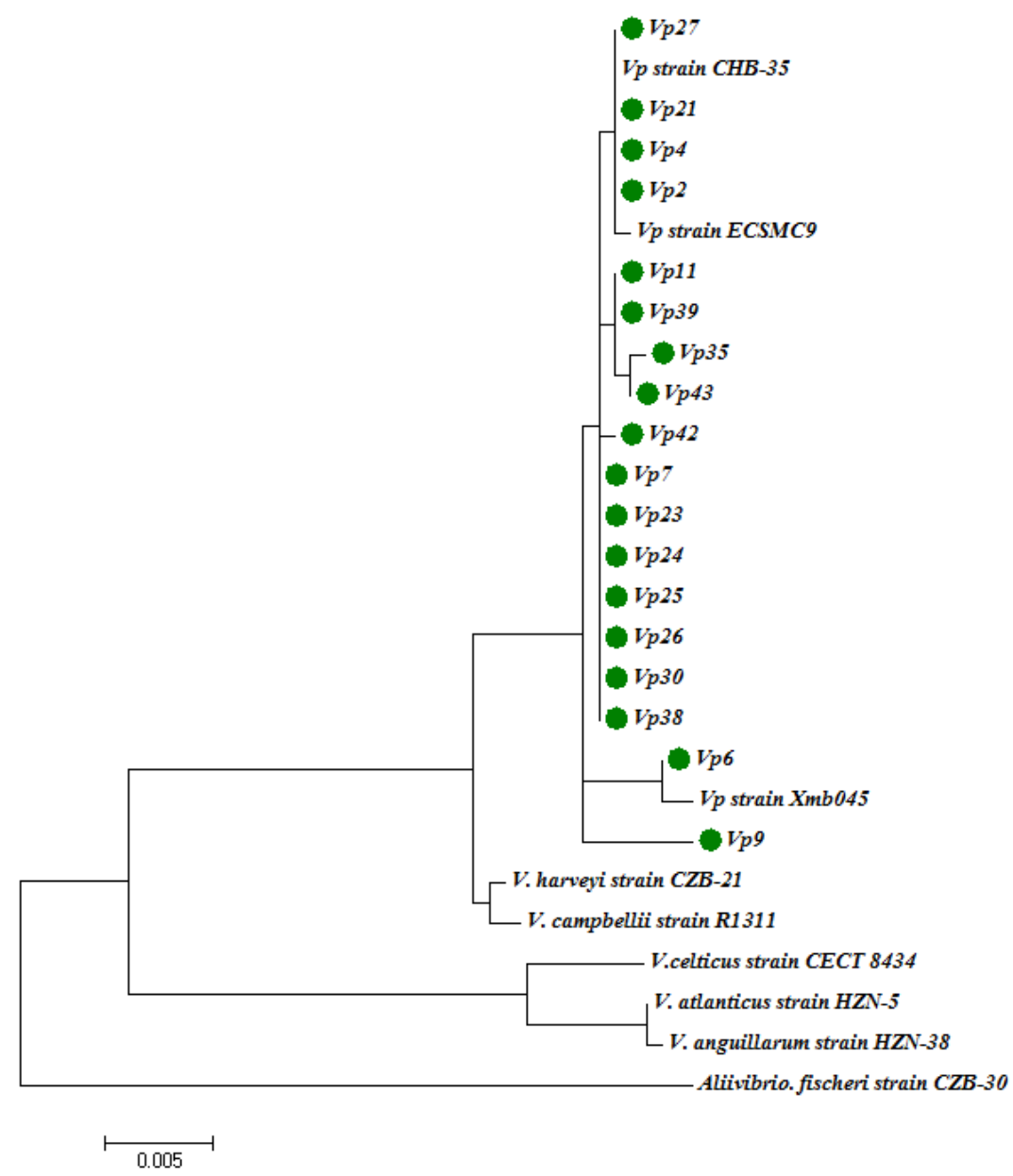

Fig. 2. Molecular phylogenetic analysis of 18 representative $V$. parahaemolyticus isolates by Maximum Likelihood method. The tree is drawn to scale, with branch lengths measured in the number of substitutions per site. There were a total of 1384 positions in the final data set. Evolutionary analyses were conducted in MEGA ${ }^{(16)}$. indicates $V$. parahaemolyticus isolates of this study.

The AP3 primers are specific for $V$. parahaemolyticus strains causing AHPND. In the present study, out of 18 representative isolates ten were found positive for AP3 specific primer (Fig. 3) and eight isolates were negative (Table 3). Kongrueng et al.(21) used AP3 that targeted to the unique DNA sequences of toxin gene of AHPND positive $V$. parahaemolyticus and found 33 positive isolates from shrimp, whereas they found negative result for all clinical and environmental isolates. In another study, SotoRodriguez et al.(20) also used AP3 primer for the detection of pathogenic and nonpathogenic $V$. parahaemolyticus strains. However, AP3 showed a false-positive result in that study (strain M06-04) and produced a predictive positive value of $90 \%$. 


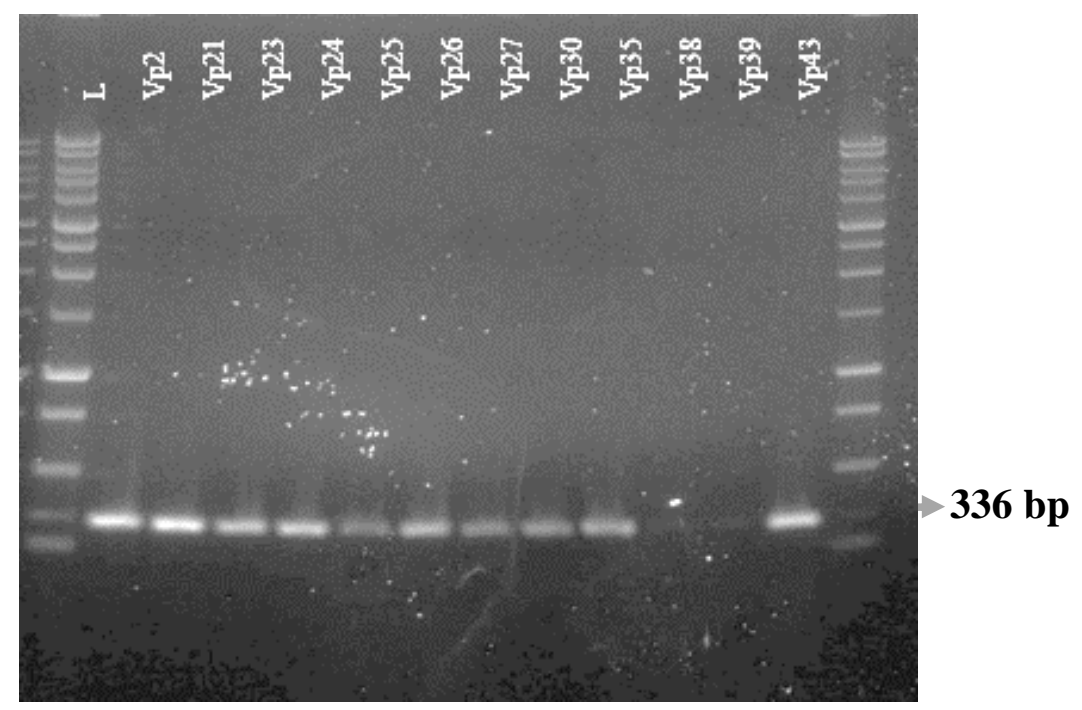

Fig. 3. PCR amplification with the primer AP3 for $V$. parahaemolyticus isolates of shrimp collected from south-west regions of Bangladesh. L denotes DNA ladder of $1 \mathrm{~kb}$ marker.

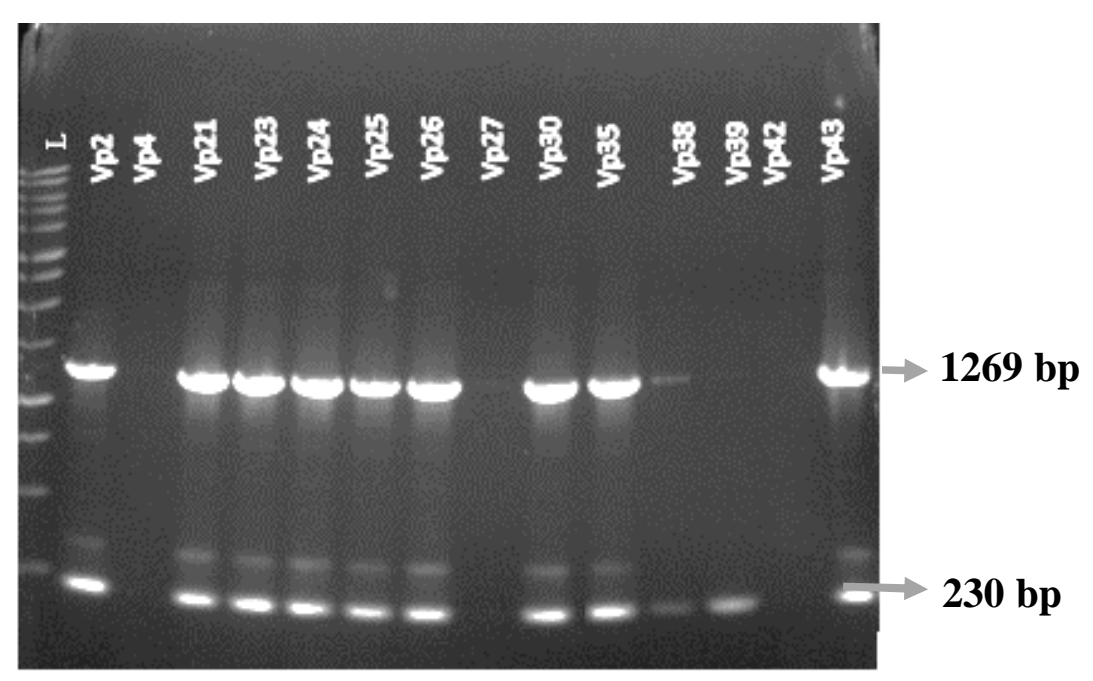

Fig. 4. Agarose gel electrophoresis of PCR amplified DNA fragments from representative $V$. parahaemolyticus isolates using AP4 nested PCR. L denotes DNA ladder of $1 \mathrm{~kb}$ marker.

The same 18 representative isolates were also subjected to PCR using AHPND specific nested primer pairs AP4. A total of the 9 isolates of $V$. parahaemolyticus were found positive (Fig. 4, Table 3). The isolates that gave positive result with AP3, same isolates gave positive result with AP4 except for Vp27.Dangtip et al. (12) worked with AP4 primers and found 51 AHPND positive V. parahaemolyticus out of 104 bacterial isolates. 
All representative 18 isolates of $V$. parahaemolyticus were resistant to the antibiotic gentamycin whereas all isolates showed $100 \%$ sensitivityto chloramphenicol, nitrofurantoin, tetracycline and nalidixic acid (Table 4). Among 18 isolates of $V$. parahaemolyticus, 15 isolates were intermediate and 3 showed sensitivity to Ciprofloxacin. On the other hand, 16 isolates showed Amikacin sensitivity and 2 isolates were intermediate but no resistant isolate was found. All isolates of Vibrio parahaemolyticus showed various level of sensitivity pattern to ampicillin, erythromycin, streptomycin and sulphamethoxazole. De Melo et al.(22) and Xu et al.(19) reported antibiotic susceptibility of $V$. parahaemolyticus isolates from shrimp and other aquatic products and found various levels of sensitivity against seven and 12 antimicrobial agents, respectively. Their studies indicate considerable risk of development of antibiotic resistance throughout the food chain.

Table 3. Detection of AHPND positive V. parahaemolyticus isolates using AP3 and AP4 primer based PCR assay.

\begin{tabular}{|c|c|c|c|}
\hline $\begin{array}{l}\text { Isolate } \\
\text { name }\end{array}$ & Region & $\begin{array}{c}\text { AP3 primer based } \\
\text { PCR assay }\end{array}$ & $\begin{array}{c}\text { AP4 primer based } \\
\text { PCR Assay }\end{array}$ \\
\hline Vp2 & Satkhira & + & + \\
\hline Vp4 & $"$ & - & - \\
\hline Vp6 & $"$ & - & - \\
\hline Vp7 & $"$ & - & - \\
\hline Vp9 & $"$ & - & - \\
\hline Vp11 & $"$ & - & - \\
\hline Vp21 & $"$ & + & + \\
\hline Vp23 & $"$ & + & + \\
\hline Vp24 & $"$ & + & + \\
\hline Vp25 & $"$ & + & + \\
\hline Vp26 & $"$ & + & + \\
\hline Vp27 & $"$ & + & - \\
\hline Vp30 & $"$ & + & + \\
\hline Vp35 & Bagerhat & + & + \\
\hline Vp38 & $"$ & - & - \\
\hline Vp39 & $"$ & - & - \\
\hline Vp42 & $"$ & - & - \\
\hline Vp43 & $"$ & + & + \\
\hline
\end{tabular}


Table 4. Percentage of antibiotic susceptibility for $18 \mathrm{~V}$. parahaemolyticus isolates against 14 antibiotics.

\begin{tabular}{llll}
\hline \multirow{2}{*}{ Name of Antibiotics } & \multicolumn{3}{l}{ Isolates of bacteria $(\mathrm{N}=18)$} \\
\cline { 2 - 4 } & $\mathrm{R}(\%)$ & $\mathrm{I}(\%)$ & $\mathrm{S}(\%)$ \\
\hline Amikacin (AK) $(30 \mu \mathrm{g})$ & 0 & 11.11 & 88.89 \\
Amoxycillin (AML) $(10 \mu \mathrm{g})$ & 88.89 & 5.56 & 5.56 \\
Ampicillin (AMP) $(10 \mu \mathrm{g})$ & 44.45 & 0 & 55.55 \\
Chloramphenicol $(\mathrm{C})(30 \mu \mathrm{g})$ & 0 & 0 & 100 \\
Ciprofloxacin (CIP) $(5 \mu \mathrm{g})$ & 0 & 16.67 & 83.33 \\
Erythromycin (E) $(15 \mu \mathrm{g})$ & 38.89 & 5.55 & 55.55 \\
Gentamycin (CN) $(10 \mu \mathrm{g})$ & 100 & 0 & 0 \\
Kanamycin (K) $(30 \mu \mathrm{g})$ & 0 & 44.45 & 55.55 \\
Nalidixic acid (NA) $(30 \mu \mathrm{g})$ & 0 & 0 & 100 \\
Nitrofurantoin (F) $(300 \mathrm{unit})$ & 0 & 0 & 100 \\
Polymyxin B (PB) $(300 \mathrm{unit})$ & 11.11 & 0 & 88.89 \\
Streptomycin (S) $(10 \mu \mathrm{g})$ & 11.11 & 44.45 & 44.45 \\
Sulphamethoxazole (SXT) $(25 \mu \mathrm{g})$ & 22.22 & 44.45 & 33.33 \\
Tetracycline (TE) $(30 \mu \mathrm{g})$ & 0 & 0 & 100 \\
\hline
\end{tabular}

${ }^{*} \mathrm{R}=$ Resistant, $\mathrm{S}=$ Sensitive, $\mathrm{I}=$ Intermediate.

In this study, $V$. parahaemolyticus, the causative agent of AHPND, was primarily identified from shrimp farming regions of Bangladesh using molecular approaches (ldh gene PCR, 16S rRNA sequencing, AP3 and AP4 nested PCR assays). The presence of positive isolates indicates the possibility of future outbreaks of AHPND in Bangladesh. Regular monitoring and effective bio-security measures should be necessary to save the shrimps from emerging disease outbreaks and to prevent huge economic loss from shrimp sector.

\section{Acknowledgements}

The authors would like to thank Md. Munjur Hossain, Utpal Chandra Roy and Md. Monwarul Islam, MS research students of Department of Fisheries, University of Dhaka, Bangladesh, and Ariful Islam, Scientific officer, Shrimp Research Station, BFRI, Bagerhat for their assistance during sampling. They are also grateful to Sheik Md. Selim Al Din, Invent Technologies for his generous support during laboratory work. This study was funded by Ministry of Science and Technology, Government of the People's Republic of Bangladesh special allocation project for the year 2015-16. 


\section{References}

1. Food and Agriculture Organization (FAO) of the United Nations 2013. Report of the FAOMARD technical workshop on Early Mortality Syndrome (EMS) or Acute Hepatopancreatic Necrosis Syndrome (AHPNS) of cultured shrimp (under TCP NIE/3304).Hanoi, Viet Nam, 25-27 June 2013. FAO Fisheries and Aquaculture ReportNo. 1053. 54 pp.

2. Boonyawiwat V, T Patanasatienkul, J Kasornchandra, C Poolkhet, S Yaemkasem, L Hammell and J Davidson 2017. Impact of farm management on expression of early mortality syndrome/acute hepatopancreatic necrosis disease (EMS/AHPND) on penaeid shrimp farms in Thailand. J. Fish Dis. 40(5): 649-659doi: 10.1111 亿fd, 12545.

3. Flegel TW 2012. Historic emergence, impact and current status of shrimp pathogens in Asia. J. Invertebr. Pathol. 110:166-173.

4. NACA (Network of Aquaculture Centres in Asia Pacific) 2012. Diseases of crustaceans - acute hepatopancreatic necrosis syndrome (AHPNS). This disease card was prepared based on the outcome s of the Asia Pacific Emergency Regional Consultation on Early Mortality Syndrome (EMS)/Acute Hepatopancreatic Necrosis Syndrome (AHPNS) held in Bangkok, Thailand, on 9-10 August 2012. 5m Publishing, Sheffield.

5. Tran L, L Nunan, RM Redman, LL Mohney, CR Pantoja, K Fitzsimmons and DV Lightner 2013. Determination of the infectious nature of the agent of acute hepatopancreatic necrosis syndrome affecting penaeid shrimp. Dis. Aquat. Organ. 105: 45-55.

6. Joshi J, J Srisala, VH Truong, B Nuangsaeng, O Suthienkul, CF Lo, TWFlegel, K Sritunyalucksana and S Thitmadee 2014. Variation in Vibrio parahaemolyticus isolates from a single Thai shrimp farm experiencing an outbreak of acute hepatopancreatic necrosis disease (AHPND). Aquaculture 428-429: 297-302.

7. Taniguchi H, H Ohta, M Ogawa and Y Mizuguchi 1985. Cloning and expression in Escherichia coli of Vibrio parahaemolyticus thermostable direct hemolysin and thermolabile hemolysin genes. J. Bacteriol. 162(5): 510-515.

8. Bej AK, P Patterson, CW Brasher, MC Vickery, DD Jones and CA Kaysner 1999. Detection of total and hemolysin-producing Vibrio parahaemolyticus in shell fish using multiplex PCR amplification of $t h$, $t d h$ and trh. J. Microbiol. Meth. 36: 215-225.

9. Lane DJ1991. 16S/23S rRNA sequencing. In: Nucleic acid techniques in bacterial systematics (Stackebrandt E \& M Goodfellow Eds.), 1st edn, pp 115-163. John Wiley \& Sons, Chichester, England.

10. Frank JA, CI Reich, S Sharma, JS Weisbaum, BA Wilson and GJ Olsen 2008. Critical evaluation of two primers commonly used for amplification of bacterial $16 \mathrm{~S}$ rRNA Genes. Appl. Environ. Microbiol. 74(8): 2461-2470.

11. Sirikharin R, S Taengchaiyaphum, K Sritunyalucksana, S Thitamadee, TW Flegel and R Mavichak 2014. A new and improved PCR method for detection of AHPND bacteria.http://www.biotec.or.th/BIOTECen2015/images/stories/News/2014/NewPCR/AP3 \%20PCR\%20detection\%20method\%20announcement.pdf, accessed on 21 July 2017.

12. Dangtip S, R Sirikharin, P Sanguanrut, S Thitamadee, K Sritunyalucksana, S Taengchaiyaphum, R Mavichak, P Proespraiwong and TWFlegel 2015. AP4 method for two-tube nested PCR detection of AHPND isolates of Vibrio parahaemolyticus. Aquac. Rep. 2: 158-162. 
13. APHA 1998. Standard Methods for the Examination of Water and Wastewater. 20 ${ }^{\text {th }}$ edition, APHA, Washington DC.1325 pp.

14. Rahman, MS, ME Martino, B Cardazzo, P Facco, P Bordin, R Mioni, E Novelli and L Fasolato 2014. Vibrio trends in the ecology of the Venice Lagoon. Appl. Environ. Microbiol. 80: 23722380.

15. Punom, NJ, AKMM Hasan, W Haque, MK Begum and MS Rahman 2016. 16S rRNA sequence based identification of pathogenic gut microbiota of Rohu Labeorohita (Hamilton-Buchanan 1822) and Silver Carp Hypophthalmichthy smolitrix (Valenciennes 1844). Dhaka Univ. J. Biol. Sci. 25(2): 169-184.

16. Kumar S, G Stecher, D Peterson and AFilipski 2016. MEGA6: Molecular Evolutionary Genetics Analysis Version 6.0. Mol. Biol. Evol. 30: 2725-2729.

17. Tamura K and M Nei 1993. Estimation of the number of nucleotide substitutions in the control region of mitochondrial DNA in humans and Chimpanzees. Mol. Biol. Evol. 10: 512-526.

18. Bauer AW, WMM Kirby, JC Sherris and M Truck 1966. Antibiotic susceptibility testing by a standardized single disk method. Am. J. Clin. Pathol. 45: 493-496.

19. Xu X, J Cheng, Q Wu, J Zhang and T Xie 2016. Prevalence, characterization, and antibiotic susceptibility of Vibrio parahaemolyticus isolated from retail aquatic products in North China. BMC Microbiol. 16: 32.

20. Soto-Rodriguez SA, B Gomez-Gill, R Lozano-olvera, M Betancourt-Lozano and SM MoralesCovarrubias 2015. Field and experimental evidence of Vibrio parahaemolyticus as the causative agent of acute hepatopancreatic necrosis disease of cultured shrimp (Litopenaeus vannamei) in Northwestern Mexico. Appl. Environ. Micriobiol. 81(5): 1689-1698.

21. Kongrueng J, M Yingkajorn, S Bunpa, N Sermwittayawong, K Sngkhamanan and V Vuddhakul 2014. Characterization of Vibrio parahaemolyticus causing acute hepatopancreatic necrosis disease in southern Thailand. J. Fish Dis. 38(11): 957-66.

22. De Melo LMR, D Almeida, E Hofer, CMF dos Reis, GND Theophilo, AFM Santos and RHSF Vieira 2011. Antibiotic resistance of Vibrio parahaemolyticus isolated from pond-reared Litopenaeus vannamei marketed in natal, Brazil. Braz. J. Microbiol. 42(4): 1463-1469. 